\title{
Modeling growth of different developmental stages in bivalves
}

\author{
H. Jörg Urban* \\ Section for Comparative Ecosystem Research, Alfred Wegener Institute for Polar and Marine Research, Postfach 120161 , \\ 27515 Bremerhaven, Germany
}

\begin{abstract}
The 5 most common growth models (Gompertz, Special von Bertalanffy, Richards, Logistic and Generalized von Bertalanffy) were fitted to growth data comprising different developmental stages (i.e. free-swimming larvae, plantigrades, post-larvae and juveniles/adults) of the Caribbean pearl oyster Pinctada imbricata. As criteria for determining the most suitable model, the mean deviation of the data from the estimated growth curve (= mean square error, MSE), the deviation of the estimated asymptotic length of the observed maximum length obtained from a natural population, and the plot of the residuals against estimates were used. The Special von Bertalanffy and Richards models produce pure asymptotic curves and are therefore unable to simulate the exponential growth of the first 2 developmental stages (free-swimming larvae and plantigrades). Furthermore they tend to overestimate the asymptotic length. Gompertz, Logistic and the Generalized von Bertalanffy model, in contrast, produce sigmoid curves and thus are much more capable of modeling growth of the combined developmental stages, thereby, however, underestimating asymptotic length. Of all models, the Generalized von Bertalanffy model yields the best fit which is explained and discussed as a special mathematical property of its surface factor ' $\mathrm{D}$ '.
\end{abstract}

KEY WORDS: Growth models $\cdot$ Modeling $\cdot$ Development $\cdot$ Bivalves $\cdot$ Pinctada imbricata

\section{INTRODUCTION}

Growth, defined as the increase in length or weight per time unit, is a significant aspect in the study of the dynamics of marine species. Regarding bivalve growth, a good overview of published results is given in Vakily (1992) and Brey (1995). Both authors used large databases compiled from literature to compare the growth of different bivalve populations. To quantify growth, the general approach is to fit mathematical models to data, such as those of Gompertz (1825) and Richards (1959). The most common used model is the von Bertalanffy growth model (VBGF), among other reasons, because it incorporates an interesting physiological concept which was first introduced by von Bertalanffy (1938) and further

*E-mail: jurban@awi-bremerhaven.de developed by Pauly (1979). Accordingly, growth is the net result of anabolism and catabolism. Substances necessary for anabolism enter through a surface which increases according to Eq. (1), and catabolism corresponds to weight, which increases according to Eq. (2).

$$
\begin{aligned}
& S=p L^{a} \\
& W=q L^{b}
\end{aligned}
$$

with $S=$ surface, $L=$ length, $W=$ weight $, p, q=$ constants, and $a, b=$ exponents.

The original function defined by von Bertalanffy (1938) is a special case as surface and weight increase isometrically (i.e. exponent $a$ of Eq. (1) $=2$ and exponent $b$ of Eq. (2) $=3$. Thus the original VBGF (von Bertalanffy 1938) is called 'Special VBGF', compared to the 'Generalized VBGF' which is without these constraints (Pauly 1979). 
Table 1. Pinctada imbricata. Growth parameters of different models with growth data of all developmental stages. $\mathrm{n}=268$; $L_{\infty}$ : asymptptoc length; $K$ : growth factor; $t_{0}$ : theoretical age at length $0 ; t_{i}$ : age at inflexion point (yr); MSE: mean square error; VBGF: von Bertalanffy growth function; Deviation of $L_{\infty}$ from $L_{\max }$ : Dev. $\left.=\sqrt{\left(L_{\infty}-L_{\max }\right)^{2}} ; L_{\max }=84 \mathrm{~mm}\right)$

\begin{tabular}{|c|c|c|c|c|c|c|c|}
\hline Model & $\begin{array}{c}L_{\infty} \\
(\mathrm{mm})\end{array}$ & $\begin{array}{c}K \\
\left(\mathrm{yr}^{-1}\right)\end{array}$ & $t_{0}$ or $t_{i}$ & $\begin{array}{c}D \\
\left(\mathrm{yr}^{-1}\right)\end{array}$ & MSE & $r^{2}$ & $\begin{array}{l}\text { Deviation of } \\
L_{\infty} \text { from } L_{\text {max }}\end{array}$ \\
\hline Gompertz & 53.9 & 3.340 & 0.414 & & 5.860 & 0.981 & 30.1 \\
\hline Special VBGF & 162.7 & 0.365 & 0.047 & & 5.776 & 0.981 & 78.7 \\
\hline Richards & 165.6 & 0.365 & -0.001 & 1.018 & 5.776 & 0.981 & 81.6 \\
\hline Logistic & 48.6 & 6.106 & 0.503 & & 8.280 & 0.973 & 35.4 \\
\hline Generalized VBGF & 65.7 & 1.767 & 0.000 & 1.765 & 4.799 & 0.984 & 18.3 \\
\hline
\end{tabular}

However, all growth models are normally used to describe the growth of adults, thus limiting their applicability to the complete life history of bivalves, as different developmental stages may display different growth patterns. Most marine bivalves have an initial free-swimming larval stage followed by a post-larval stage. These 2 stages grow linearly or exponentially (e.g. Beaumont \& Budd 1982, Rose \& Baker 1994), whereas adult growth - in the case of growth in length — is asymptotical. Bayne (1965), examining the growth of Mytilus edulis, showed linear growth for larvae and asymptotic growth for adults. Both developmental stages were analyzed independently.

Based on this consideration the present study intends to evaluate the suitability of different historical growth models to explain the growth of all developmental stages in bivalves. Firstly, the growth rates of different developmental stages of a marine bivalve were compared. All obtained growth data were then fitted to the different models. Growth data of the Caribbean pearl oyster Pinctada imbricata covered the following developmental stages: (1) free-swimming

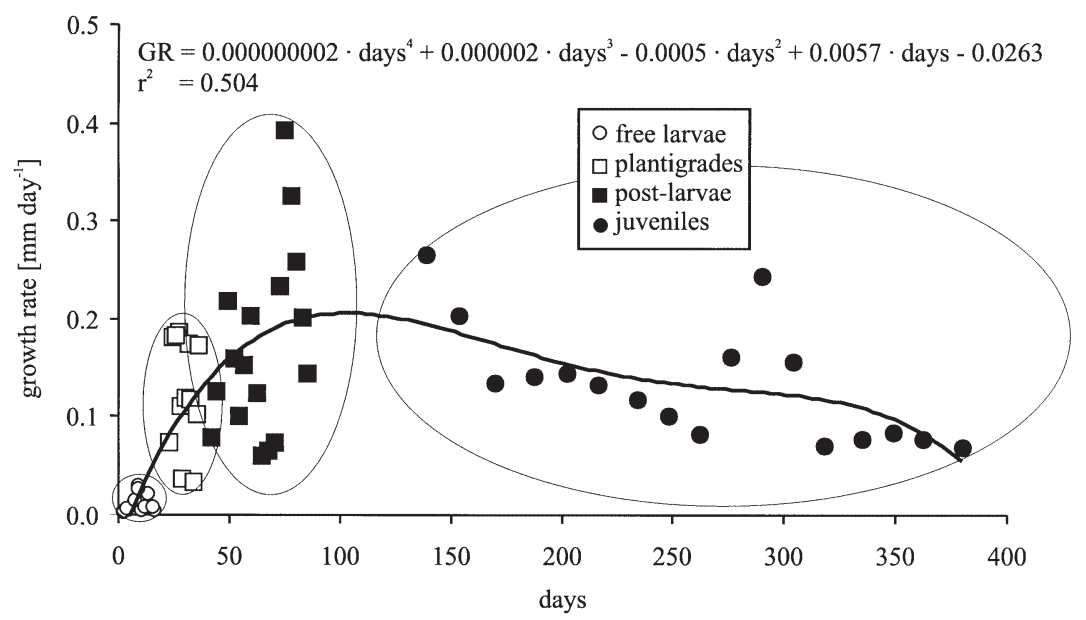

Fig. 1. Pinctada imbricata. Mean daily growth rates of different developmental stages. The equation shown is the polynomial of the 4 th order fitted to the data. GR: growth rate larvae reared in the laboratory, (2) mobile plantigrades reared in the laboratory, (3) sessile post-larvae grown in culture systems in the field and (4) juveniles/adults cultured in the field.

\section{MATERIALS AND METHODS}

Growth data of different developmental stages. Larval growth in the laboratory: Adult individuals of the pearl oyster Pinctada imbricata were collected from Cabo de Vela $\left(12^{\circ} 10^{\prime} \mathrm{N}, 72^{\circ} 20^{\prime} \mathrm{W}\right)$ and left for $4 \mathrm{wk}$ to adapt to laboratory conditions using ultravioletirradiated, $45 \mu \mathrm{m}$ filtered sea water kept between 23 to $25^{\circ} \mathrm{C}$ and a salinity of 34 , and fed on a $1: 1$ (by volume) mixture of Chaetoceros gracilis and Isochrysis galvana supplied by a continuous dropping system of 1 drop s ${ }^{-1}$. During a spawning trial the temperature was gradually increased by $1^{\circ} \mathrm{C}$ every $30 \mathrm{~min}$ up to $34^{\circ} \mathrm{C}$. Fertilization was initiated by mixing eggs and sperm at 1:10 (volume-ratio). Larvae (3 replicates) were transferred to $500 \mathrm{l}$ tanks filled with ultraviolet-irradiated, $1 \mu \mathrm{m}$ filtered seawater kept at $27^{\circ} \mathrm{C}$, stocked at an initial density of 6 larvae $\mathrm{ml}^{-1}$ and fed on I. galvana and C. gracilis (up until Day 15: 50000 cell ml $^{-1}$, after Day 15: 100000 cell $\mathrm{ml}^{-1}$ ), changing the water every 2 d. From Day 15 onwards a propylene net material was placed in the tanks during larval settlement. Larval growth was studied for $37 \mathrm{~d}$ by measuring the anterior-posterior length of approximately 10 to 15 larvae every $5 \mathrm{~d}$ with a microscope.

Post-larval growth under natural conditions: From Day 47 to Day 88, growth of the post-larvae obtained from the experiment described above continued under natural conditions. Fifty post-larvae (3 replicates, mean \pm $\mathrm{SD})$ measuring $2.9 \pm 0.675 \mathrm{SD}$ mm shell length, chosen randomly from the lar- 
val experiments, were held in suspended boxes (plastic boxes, 40 length $\times 60$ width $\times 15$ height $[\mathrm{cm}]$, covered by propylene nets of $0.7 \mathrm{~cm}$ mesh size) at $5 \mathrm{~m}$ depth in the sea situated in the near vicinity of the laboratory $\left(11^{\circ} 20^{\prime} \mathrm{N}, 74^{\circ} 10^{\prime} \mathrm{W}\right)$. The length on the anteriorposterior axis of 30 individuals was measured every $5 \mathrm{~d}$ using vernier calipers.

Growth of juveniles/adults in suspended boxes: Juveniles were obtained as natural spat from collectors (see Urban 2000a) with an initial shell length of $12.8 \pm$ $1.881 \mathrm{~mm}$. Growth of individuals from 3 replicates was monitored between September 1997 and June 1998 in suspended boxes (plastic boxes, 40 length $\times 60$ width $\times$ 15 height $[\mathrm{cm}]$, covered by propylene nets of $0.7 \mathrm{~cm}$ mesh size) at a density of $30 \%$ (= percentage of the available area covered). Boxes were connected to vertical lines on a bottom long line kept in the water column at least $5 \mathrm{~m}$ above the bottom and $5 \mathrm{~m}$ below the surface. Long line systems were located at Gayraca Bay in the Tayrona Park $\left(11^{\circ} 20^{\prime} \mathrm{N}, 74^{\circ} 10^{\prime} \mathrm{W}\right.$, see Urban 2000b). Anterior-posterior shell length of 30 individuals was measured monthly (vernier calipers). Culture systems were cleaned at the same time.

Analysis of growth data. As an initial step, based on means of all individuals of 3 replicates of each measuring date, mean growth rates of shells $\left[\mathrm{mm} \mathrm{d}^{-1}\right]$ were calculated. In a second step, different growth models (Gompertz Eq. 3, Special VBGF Eq. 4, Richards Eq. 5, Logistic Eq. 6 and Generalized VBGF Eq. 7) were fitted to length-at-age data of all developmental stages in order to estimate the parameters using an iterative non-linear least-square method (Simplex algorithm, Press et al. 1986).

$$
\begin{array}{ll}
\text { Gompertz: } & L_{t}=L_{\infty} \mathrm{e}^{\mathrm{e}^{\left[-K\left(t-t_{0}\right)\right]}} \\
\text { Special VBGF: } & L_{t}=L_{\infty}\left(1-\mathrm{e}^{-K\left(t-t_{0}\right)}\right) \\
\text { Richards: } & L_{t}=L_{\infty}\left[1-D \mathrm{e}^{\left[-K\left(t-t_{i}\right)\right]}\right]^{1 / D} \\
\text { Logistic: } & L_{t}=\frac{L_{\infty}}{\left(1+\mathrm{e}^{-K\left(t-t_{0}\right)}\right)} \\
\text { Generalized VBGF: } & L_{t}=L_{\infty}\left(1-\mathrm{e}^{-K\left(t-t_{0}\right)}\right)^{D}
\end{array}
$$

where $L_{\infty}=$ asymptotic length (mm), $K$ and $D_{\text {Richards }}=$ growth parameters $\left(\mathrm{yr}^{-1}\right), D_{\mathrm{Gen} \text { VBGF }}=$ surface factor, $t=$ age (yr), $t_{0}=$ theoretical age at zero length, and $t_{i}=$ age at the inflexion point (yr).

\section{RESULTS}

Mean daily growth rates for all developmental stages are plotted in Fig. 1. Clearly the 4 developmen- tal stages exhibit different growth rates, each represented by an ellipsoid in Fig. 1. From free-swimming larvae to plantigrades and post-larvae, both growth rates and variability increase reaching a maximum at about $90 \mathrm{~d}$. Growth rate of juveniles decreases almost asymptotically with the exception of a peak at $300 \mathrm{~d}$. A polynomial of the 4 th order was fitted to these data accounting for $50 \%$ of the variability of growth rates $\left(\mathrm{r}^{2}=0.504\right)$.

The growth parameters estimated with the 5 different models are summarized in Table 1. To evaluate the fit of the data, the residuals (of years) were plotted against estimated shell length (Fig. 2a). The corresponding growth curves were plotted over the raw data (shell length against years, Fig. 2b).

\section{DISCUSSION}

Fig. 1 shows a remarkable growth increase from Day 23 onwards. According to the morphological development, the free-swimming larvae developed into plantigrades after $23 \mathrm{~d}$, having acquired branchial filaments some days before. Thus the growth difference between these 2 stages can be explained by the fact that individuals with a fully functional feeding apparatus were able to feed on the available phytoplankton at a much higher rate than the previous larval stage.

Growth rates of juveniles reached a small peak at $300 \mathrm{~d}$ (Fig. 1) although according to the growth model one would expect an asymptotic decrease. Urban (2000b) related the growth rates of this data set (only juveniles) to different abiotic factors. One month before growth increase, an increase of particulate organic matter (POM) was observed in the water. In the study area the POM cycle depends on a seasonal pattern of the rainy season (POM increase owing to run-off induced by rainfall). Thus, an oscillating growth pattern is indicated, although, due to little or no seasonality in the tropics, non-oscillating growth is usually assumed.

Based on the graphical results in Fig. 2a and the estimated parameters, and referring to the statistics given in Table 1, 3 criteria were used to evaluate the 5 models: (1) the plot of residuals, (2) the mean deviation of the data from the estimated curve (given by the mean square error, MSE), and (3) the deviation of the estimated $L_{\infty}$ from the maximum length of the natural population.

The latter can be explained as follows: Urban (2000a) studied the population dynamics of this species from Cabo de la Vela. From pooled monthly samples over 1 yr of more than 1000 specimens, a maximum length of $L_{\max }=84 \mathrm{~mm}$ was obtained. It can be assumed that this $L_{\text {max }}$ is close to the true biological $L_{\infty}$. However, it is 


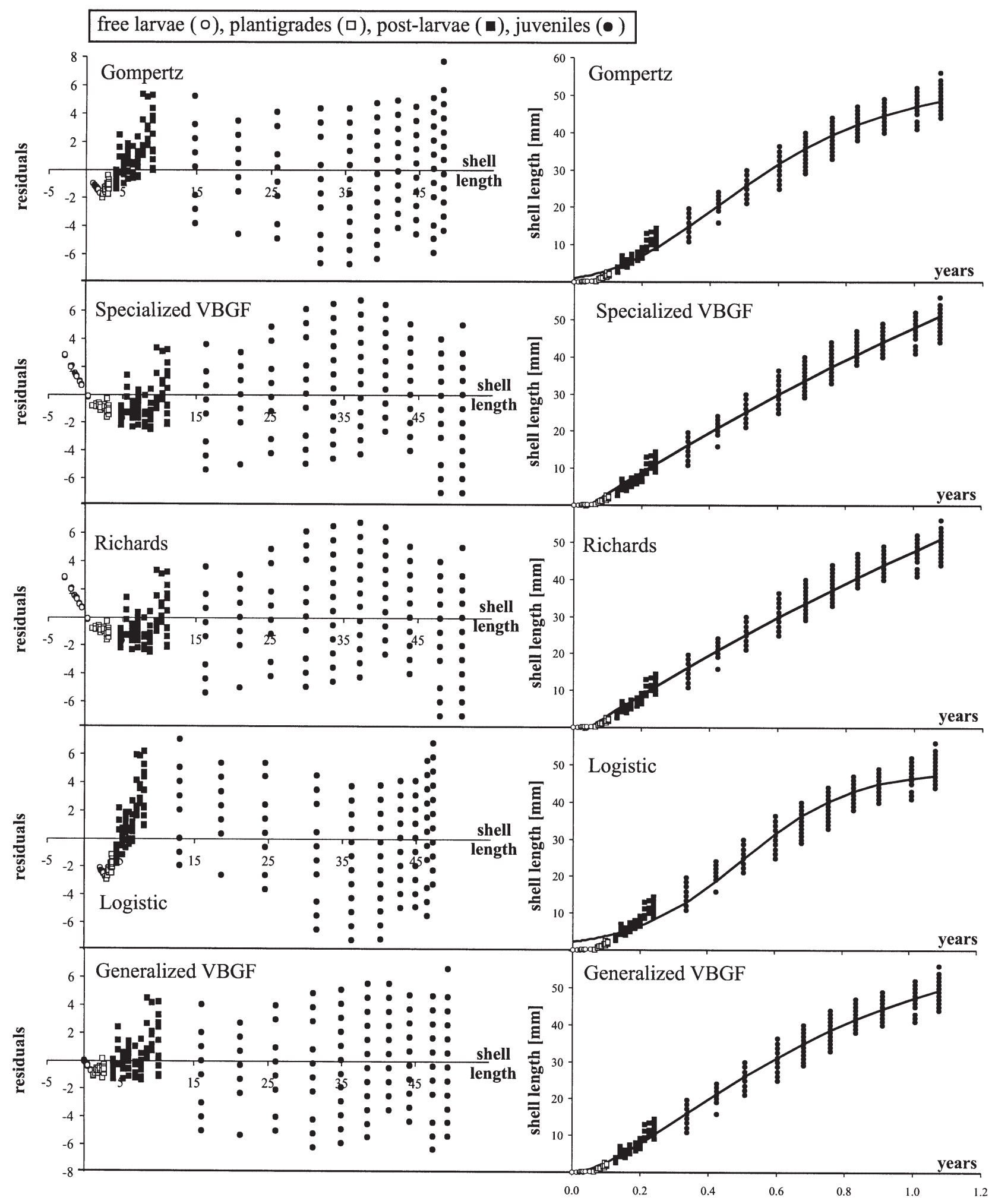

a)

b)

Fig. 2. Pinctada imbricata. (a) Plot of residuals of estimated shell lengths for 5 growth models of different developmental stages. (b) Shell length (mm) plotted against age (yr) 
well known that the estimated $L_{\infty}$ may differ considerably from $L_{\max }$ if growth data do not cover most of the species' growth range (Ralph \& Maxwell 1977, Urban \& Mercuri 1998). This applies to the present data set because growth followed for only $12 \mathrm{mo}$. The deviation of the estimated $L_{\infty}$ from the maximum length of the natural population was calculated as:

$$
\text { Deviation }=\sqrt{\left(L_{\infty}-L_{\max }\right)^{2}}
$$

By plotting the residuals against the estimated shell lengths the randomness of their distribution can be evaluated (Fig. 2a). For the Special VBGF and Richards, a strong linear trend of the first 2 stages and a nonlinear trend of the last stage (juveniles/adults) is clearly expressed. In the Logistic and Gompertz, these trends are similar but less clear, while for the Generalized VBGF they are not pronounced, indicating an acceptable fit of the data. This leads to the following ranking of the models (beginning with best fit): Generalized VBGF, Gompertz/Logistic, Special VBGF/ Richards. According to the MSE, the models can be arranged in the following order (from smallest to highest MSE): (1) Generalized VBGF, (2) Special VBGF, (3) Richards, (4) Gompertz and (5) Logistic. For the deviation of $L_{\infty}$ from $L_{\max }$ the ranking of the models is different: The smallest deviation was also found for the Generalized VBGF (=18.3 mm), followed by the Gompertz $(=30.1 \mathrm{~mm})$ and the Logistic $(=35.4 \mathrm{~mm})$. High deviations were obtained for the Special VBGF $(=78.7 \mathrm{~mm})$ and Richards $(=81.6 \mathrm{~mm})$.

So far the following conclusions can be drawn: The maximum growth rates at $90 \mathrm{~d}(=0.25 \mathrm{yr}$, Fig. 1) corresponds to the point of inflexion of the sigmoid curves in Fig. 2b. In other words, owing to the maximum growth rates of Fig. 1, growth data of Fig. 2 are difficult to simulate with a simple asymptotic growth model. Instead, a model capable of explaining all stages of the sigmoid character of the growth data is more suitable. The Special VBGF and Richards produce pure asymptotic curves, thus they are unable to simulate the near-exponential larval growth. Furthermore, they tend to overestimate $L_{\infty}$ indicated by the high deviation of $L_{\infty}$ from $L_{\max }$. Such high values for the estimated $L_{\infty}$ (Special VBGF: $162.7 \mathrm{~mm}$; Richards: $165.6 \mathrm{~mm}$ ) are completely out of this species' growth range and therefore without biological relevance. The Generalized VBGF, Logistic and Gompertz, produce sigmoid curves and thus are much more capable of modeling the growth of these bivalves. They tend to underestimate $L_{\infty}$, but in all 3 cases the deviation of $L_{\infty}$ from $L_{\max }$ is less than in the Special VBGF and Richards. Among the sigmoid curves, Gompertz and the Logistic model clearly fail to explain the growth of the first 2 developmental stages (up to $0.1 \mathrm{yr}$ ). The Generalized VBGF, however, appears to explain growth of all developmental stages including the larval stages, although the fit for the first developmental stage is not optimal. Thus, from all models compared the Generalized VBGF is clearly the most suitable.

In order to explain these findings some mathematical properties of the models have to be discussed. The Generalized VBGF used here differs from the Special VBGF only by the surface factor $D$, defined as $D=b-a$ $(b, a$ : exponents of Eqs. 1 \& 2). The ' $D$ '-parameter is also found in Richards model, and indeed, as stated by Pauly (1981), Richards model is a 'first version of the Generalized VBGF, ...however, without setting theoretical limits to possible values of the exponents relating anabolism and catabolism to weight'. When $D=1$, the Generalized VBGF and Richards are equal to the Specialized VBGF. A good example is given in Table 1: $D_{\text {(Richards) }}$ is almost 1, so we would expect the parameters of Richards to be equal or similar to the parameters of the Special VBGF. As it turns out, both $K$-values are equal and the $L_{\infty}$ values are very similar. However, the parameters $D$ in the Generalized VBGF and Richards model have different modeling properties taking into account that Richards produced an asymptotic curve, while Generalized VBGF resulted in a sigmoid curve. Pauly (1981) mentions as an 'interesting property' of the Generalized VBGF the occurrence of an inflexion point when $D_{\text {(Generalized VBGF) }}>1$ and no inflexion point when $D=1$. (The original paper says ' $D<1$ ', but I assume this must be a printing error.)

In other words, when $D_{\text {(Generalized VBGF) }} \leq 1$ the curve is asymptotic and only when $D_{\text {(Generalized VBGF) }}>1$ does the curve become increasingly sigmoid. On the other hand, $D_{\text {(Richards) }}$ merely shifts the entire growth curve on the abscissa without changing its form.

In summary, when $D_{\text {(Generalized VBGF) }}>1$, the Generalized VBGF has an inflexion point, in other words the asymptotic curve is changed into a sigmoid curve, thus, giving the best fit to the data consisting of all developmental stages.

Acknowledgements. Juan Pablo Assmus, Socorro Sánchez and Yadira Caballero helped in the field and worked on the samples. Considerations of Dr. T. Brey regarding data analysis were helpful, and several constructive critics of 4 referees improved this paper. The idea for this paper was born several years ago after discussing this subject with Dr. D. Pauly.

\section{LITERATURE CITED}

Bayne BL (1965) Growth and the delay of metamorphosis of the larvae of Mytilus edulis (L.). Ophelia 2(1):1-47

Beaumont AR, Budd MD (1982) Delayed growth of mussel (Mytilus edulis) and scallop (Pecten maximus) veligers at low temperature. Mar Biol 71:97-100

von Bertalanffy L (1938) A quantitative theory of organic 
growth (Inquiries on growth laws. II). Human Biol 10: 181-213

Brey T (1995) Empirische Untersuchungen zur Populationsdynamik makrobenthischer Evertebraten. Habilitation thesis, University of Bremen

Gompertz B (1825) On the nature of the function expressive of human mortality, and on a new mode to determining the value of life contingencies. Philos Trans R Soc Lond 115: $513-585$

Pauly D (1979) Gill size and temperature as governing factors in fish growth: a generalization of von Bertalanffy's growth formula. Ber Inst Meereskd Christian-AlbrechtsUniv Kiel 63

Pauly D (1981) The relationship between gill surface area and growth performance in fish: a generalization of von Bertalanffy's theory on growth. Meeresforschung 28: 251-282

Press WH, Flannery BP, Teukolsky SA, Vetterling WT (1986) Numerical recipes: the art of scientific computing. Cambridge University Press, Cambridge

Ralph R, Maxwell JGH (1977) Growth of two Antarctic lamel-

Editorial responsibility: Otto Kinne (Editor),

Oldendorf/Luhe, Germany libranchs: Adamussium colbecki and Laternula elliptica. Mar Biol 42:171-175

Richards FF (1959) A flexible growth function for empirical use. J Exp Bot 10:290-300

Rose RA, Baker SB (1994) Larval and spat culture of the Western Australian silver or goldlip pearl oyster, Pinctada maxima (Jameson) (Mollusca: Pteriidae). Aquaculture 126:35-50

Urban HJ (2000a) Aquaculture potential of the Caribbean pearl oyster Pinctada imbricata I. Gametogenic activity, growth, mortality and production of a natural population. Aquaculture 189:361-373

Urban HJ (2000b) Aquaculture potential of the Caribbean pearl oyster Pinctada imbricata II. Larvae and spat collection, juvenile growth and mortality in culture systems related to ambient conditions. Aquaculture 189:375-388

Urban HJ, Mercuri G (1998) Population dynamics of the bivalve Laternula elliptica from Potter Cove, King George Island, Antarctic Peninsula. Antartct Sci 10(2):153-160

Vakily JM (1992) Determination and comparison of growth in bivalves, with emphasis on Thailand and other tropical areas. ICLARM Tech Rep 36

Submitted: August 21, 2001; Accepted: January 31, 2002

Proofs received from author(s): July 9, 2002 